\title{
Why don't things happen the same way every time?
}

\author{
Frank W. Sellke, MD
}

\footnotetext{
From the Division of Cardiothoracic Surgery, Lifespan Cardiovascular Institute, Alpert Medical School of Brown University, Providence, RI.

Disclosures: Author has nothing to disclose with regard to commercial support.

Received for publication Sept 1, 2016; accepted for publication Sept 6, 2016; available ahead of print Oct 4, 2016. Address for reprints: Frank W. Sellke, MD, Alpert Medical School of Brown University, 2 Dudley St, MOC 360, Providence, RI 02905 (E-mail: fsellke@lifespan.org).

J Thorac Cardiovasc Surg 2016;152:1492-3

$0022-5223 / \$ 36.00$

Copyright $(2) 2016$ by The American Association for Thoracic Surgery

http://dx.doi.org/10.1016/j.jtcvs.2016.09.010
}

In this issue of the Journal, Lawton ${ }^{1}$ nicely discusses the topic of "Reproducibility and Replicability in Science and Thoracic Surgery." Variation is an intrinsic characteristic of the universe since shortly after the Big Bang, when the organization of quarks and other subatomic particles determined the exact nature of our current existence. When one wakes up, generally at the same time each day, many things are similar but not quite the same. The same holds true for research. What happens one day in the lab may not happen the same way the next day or the next week. Most of this variation is related to the different conditions under which the experiments are performed. Often we do not recognize these differences or try to minimize them. As Lawton ${ }^{1}$ mentions, these differences can be as seemingly minor as slight differences in the quality of reagents. Even the humidity, barometric pressure, and time of day probably have some impact on the results of both basic and animal experiments.

There are other reasons why results are not reproducible. There is a fair amount of bias on the part of scientists. Experiments are sometimes performed until the desired results are obtained, or selected experiments are thrown out because they are "outliers." Another issue is that experiments in otherwise normal cultured cells or mice may not replicate what is happening in patients who have diabetes, cancer, or heart disease. There have been several cases recently in which pharmaceutical companies such as Amgen and Bayer could reproduce only a small portion of the results published in the most prestigious scientific journals. ${ }^{2,3}$ Clinicians are also subject to this bias. Recent examples of this in our field are the utility of off-pump versus on-pump coronary artery bypass grafting, valve repair versus replacement for ischemic mitral insufficiency, and the potential benefit of cell therapy for heart failure. Each of these topics has had or still has strong proponents on both sides of the question.

There are also some more nefarious reasons why results are not reproducible. In an effort to get a Nobel Prize or some other mark of distinction, some investigators,

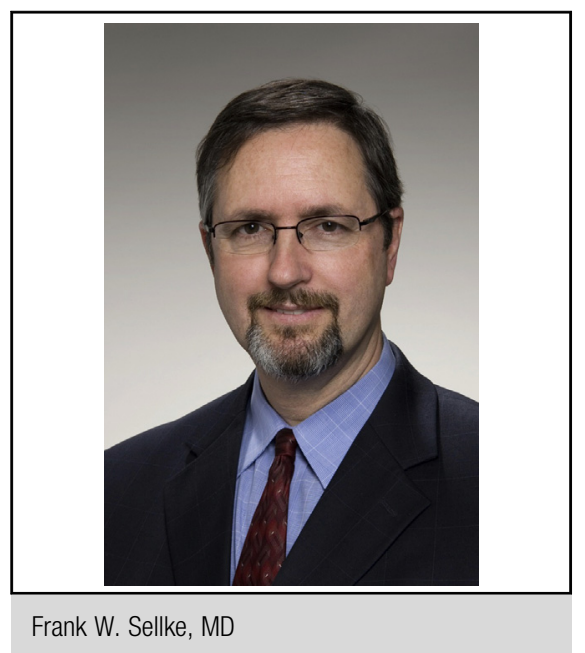

Central Message

Variation in results in research may be attributable to many factors in addition to bias. Rarely, overt fabrication of data may lead to the publication of information that cannot be repeated.

See Article page 1489 .

despite their best efforts, do not obtain the correct and expected results. They may massage the data or may only report on selected experiments. It has been said that if you torture the data enough, it will say anything that you want. There have been several recent high-profile cases in which the results were simply fabricated, with or without the laboratory director observing what was going on. It is usually the latter.

It can be understood why the US Congress and the US National Institutes of Health are concerned that they are allocating more than $\$ 30$ billion per year toward research that largely cannot be replicated. In the vast majority of cases, this is due not to overt fabrication of data but rather to poor experimental design, irrelevant models, natural variability, or incorrect interpretation of the data, in addition to the issues raised previously.

The National Institutes of Health and other organizations are mandating attention to "scientific rigor and consideration of relevant biological variables." 4 This will be part of the process of scientific investigation and especially the submission of grants. This extra scrutiny may not be all bad, because it may require us to think before we investigate a cellular pathway, a method to improve clinical care, or a novel surgical treatment. 


\section{References}

1. Lawton JS. Reproducibility and replicability of science and thoracic surgery. $J$ Thorac Cardiovasc Surg. 2016;152:1489-91.

2. Begley CG, Ellis LM. Drug development: raise standards for preclinical cancer research. Nature. 2012;483:531-3.
3. Mullard A. Reliability of 'new drug target' claims called into question. Nat Rev Drug Discover. 2011;10:643-4.

4. National Institutes of Health. Rigor and reproducibility. Available at: https:// grants.nih.gov/reproducibility/index.htm. Accessed September 29, 2016. 